\title{
TENDE BOM ÂNIMO: ANSIEDADE, DEPRESSÃO E TEOLOGIA PRÁTICA CRISTÃ.
}

BE OF GOOD CHEER: ANXIETY, DEPRESSION

AND CHRISTIAN PRACTICE THEOLOGY.

Sérgio da Cunha Falcão ${ }^{7}$

\footnotetext{
${ }^{7}$ Professor do Departamento de Crurgia da UPB (desde 1998). Doutorando em Cências dos Religöes pela UNICAP. Mestre em Saúde Pública UEPB (2013). Residência Médica em Cirurgia Geral e Grurgia Plástica UNFESP (1992-1997). Graduação em Medicina UPB (1986-1991). Graduação em Teologia FISA (2018). Professor Voluntário de Ensino Religioso da greja Batista Cidade Vua. Ex-presidente da Regional Paraiba da Sociedade Brasilera de Crurgia Plástica. MBA em Gestão de Reaursos e Liderança Cristã pela AP/ Fundação Gidade Via (2010). MBA em Gestão de Cooperativas de Crédito da UNPÊ (2013). Foi Gestor Voluntário do Ministério de Escoteros da Fundação Gdade Viva (2008-2011). Graduado pelo Instututo Haggai (2010). Foi Instrutor do Advanced Trauma Life Support (ATLS) - American College of Surgeons USP. Emait falcaocirplastic@oi.com.br
} 


\section{RESUMO}

Saúde e religião têm sido estudadas principalmente por psicólogos, médicos e enfermeiros, sendo pouco frequentes pesquisas feitas por teólogos e cientistas da religião. O presente artigo tem como objetivo refletir acerca da relação entre ansiedade, depressão e teologia prática cristã. Foi realizada revisão das evidências da literatura no banco de dados PubMed. A prevalência da ansiedade foi de 3,6\% no mundo e 9,3\% no Brasil; país mais ansioso do mundo. A depressão acomete $4,4 \%$ da população mundial e $5,8 \%$ dos brasileiros. Ao mesmo tempo, $90 \%$ da população mundial está envolvida em alguma forma de prática religiosa ou espiritual, e existem consistentes evidências que os indivíduos que têm mais religiosidade têm menos depressão, ansiedade, tentativas de suicídio e uso/abuso de drogas, e experimentam melhor qualidade de vida, remissão mais rápida dos sintomas depressivos e melhores resultados psiquiátricos. No entanto, apesar de menos prevalente, o uso negativo da religião ou da espiritualidade no lidar com os problemas da vida (coping religioso/espiritual negativo) tem sido causa de adoecimento mental e foi encontrado em algumas pesquisas. Essas relações positivas e negativas precisam ser compreendidas por líderes e conselheiros cristãos, por professores, psiquiatras, psicólogos, teólogos e cientistas da religião.

\section{PALAVRAS-CHAVE}

Ansiedade. Depressão. Religião. Cristianismo. Enfrentamento.

\section{ABSTRACT}

Health and religion have been studied mainly by psychologists, doctors and nurses, being infrequent researches done by theologians and scientists of the religion. The present article aims to reflect on the relationship between anxiety, depression and Christian practical theology. We reviewed the literature evidence in the PubMed database. The prevalence of anxiety was 3.6\% in the world and $9.3 \%$ in Brazil; most anxious country in the world. Depression affects $4.4 \%$ of the world population and $5.8 \%$ of brazilians. At the same time, $90 \%$ of the world's population is involved in some form of religious or spiritual practice, and there is consistent evidence that individuals with more religiosity have less depression, anxiety, suicide attempts and drug use, and experience 
better quality of life, faster remission of depressive symptoms and better psychiatric outcomes. However, although less prevalent, the negative use of religion or spirituality in dealing with life problems (religious / spiritual negative coping) has been a cause of mental illness and has been found in some research. These positive and negative relationships need to be understood by Christian leaders and counselors, by teachers, psychiatrists, psychologists, theologians, and religion scientists.

\section{KEYWORDS}

Anxiety. Depression. Religion. Christianity. Coping.

\section{INTRODUÇÃO}

A tragédia e a beleza da realidade existencial humana mostram que as aflições estão em nosso passado, presente e futuro; sob a forma direta e concreta ou como pensamentos, emoções e memórias. Pinturas existentes em 300 cavernas subterrâneas, no sul da França e norte da Espanha, datadas cerca de 30.000 anos antes de Cristo (a.C.), evidenciam que religião, arte, medo, coragem e cura já surgiram inseparáveis, como desejo de cultivar o senso do transcendente e busca pelo sentido/valor último da vida e bom ânimo para enfrentar o sofrimento, a culpa e a morte (ARMSTRONG, 2011; FRANKL, 2017).

Como uma das formas desse sofrimento humano, a doença mental pode acometer uma em cada quatro pessoas em dada fase da vida, tornando rara a família poupada de um encontro com perturbações mentais (ORGANIZAÇÃO MUNDIAL DE SAÚDE, 2002). No ano de 2015, a prevalência da ansiedade foi de $3,6 \%$ no mundo e 9,3\% no Brasil; país mais ansioso do mundo. Por sua vez, a depressão acomete $4,4 \%$ da população mundial e $5,8 \%$ dos brasileiros (WORLD HEALTH ORGANIZATION, 2017a). Em 2030, a depressão será a segunda causa mais comum responsável pela carga global de doenças, perdendo apenas para a VIH/SIDA e sendo mais frequente que a doença cardíaca isquêmica (MATHERS; LONCAR, 2006).

Quem tem depressão tem imunidade diminuída, maior probabilidade de desenvolver comportamentos não saudáveis, como práticas sexuais de alto risco para doenças transmissíveis e desobediência às recomendações médicas para tratamento de 
outras doenças, e maus prognósticos (ORGANIZAÇÃO MUNDIAL DE SAÚDE, 2002; ORGANIZAÇÃO MUNDIAL DE SAÚDE; ORGANIZAÇÃO MUNDIAL DE MÉDICOS DE FAMÍLIA, 2008). Estima-se que $10 \%$ das pessoas podem sofrer ao menos um episódio depressivo ao longo da vida. Dois em cada 10 casos de depressão se tornam crônicos, e dois terços das pessoas com depressão não fazem tratamento. Além disso, "a maioria dos pacientes não tratados tentará suicídio pelo menos uma vez na vida" e, destes, $17 \%$ conseguem se matar. Mas, a boa notícia é que, se forem tratados adequadamente, 70 a 90\% vão se recuperar (GOMES, 2011, p. 83).

No Brasil, as pesquisas sobre ansiedade e depressão no contexto da teologia prática cristã ainda são escassas e as relações positivas e negativas entre saúde/doença e religião são pouco compreendidas por grande parte de líderes religiosos, cientistas da religião, teólogos, psiquiatras e psicólogos que lidam com pessoas acometidas.

O presente artigo tem como objetivo refletir acerca da relação entre religião, religiosidade, espiritualidade, ansiedade e depressão, no contexto da teologia prática cristã. Serão apresentados conceitos desses temas e de coping (enfrentamento) religioso-espiritual. Como metodologia, foi realizada pesquisa bibliográfica referente ao tema do presente trabalho e utilizadas como lentes interpretativas a psicologia, a psiquiatria, as ciências da religião, a filosofia existencialista e a teologia cristã.

\section{ESPIRITUALIDADE, RELIGIÃO, RELIGIOSIDADE}

Esperandio (2014) afirma que espiritualidade é busca por propósito/sentido de vida e de relacionamento, integração e realização de um ser humano consigo mesmo, com os outros e com o transcendente (Ser Superior, força, energia, estado meditativo, etc.). Essa constante antropológica que faz o ser humano buscar relação com algo que transcende a realidade concreta de sua vida remete ao sentido etimológico das palavras latinas Religio, religatio, religare, como ligação a Deus interpretação teológica cristã de Lactâncio (240-320 d.C.) e Agostinho (354-430 d.C.) (SMITH, 2006). No contexto bíblico, embora tenhamos a lei de Deus gravada em nosso coração, nascemos afastados ou desligados do Criador e distorcemos essa lei Necessitamos desenvolver uma religação pessoal com o logos 
encarnado de Deus - Jesus -, o caminho de perdão, regeneração e santificação.

Diferentemente de espiritualidade, religiões são sistemas organizados de crenças, práticas, rituais e símbolos destinados a facilitar a aproximação ao transcendente (MOREIRA-ALMEIDA, KOENIG, LUCCHETTI, 2014; KOENIG, 2012). Sendo instituições, as religiões são comunidades formadas por indivíduos que compartilham uma mesma crença ou fé, e um corpo de doutrinas (ESPERANDIO, 2014). Por outro lado, religiosidade mostra-se como qualquer expressão humana de espiritualidade e/ou pertencimento a uma religião; variável quantificável por meio de instrumentos multidimensionais (conhecimento, sentimento, comportamento, corporeidade), etimologicamente relacionada às palavras Relegere, religiosus ou religens ("religente") como o oposto de negligens ao culto aos deuses - Cícero (106-43 a.C) (SMITH, 2006).

Assim, em sua origem histórica, a religião era considerada uma experiência objetiva de culto individual e coletivo, depois, "definida no cristianismo como uma relação pessoal com um Deus pessoal" (GOMES, 2011, p. 92). Já no século XX, o psiquiatra Carl Gustav Jung (1875_1961) definiu religião como experiência cósmica, primordial, herança psíquica inconsciente filogenética, sem referência a uma determinada confissão de fé. Essa concepção inata, universal, arquetípica e transmitida hereditariamente de Jung se aproxima da conceituação da teologia cristã da imago dei, a qual afirma que o homem foi criado à Imagem de Deus e Jesus Cristo é a completa e perfeita imagem em Plena Essência do Deus Invisível (GOMES, 2011, p. 93).

Entretanto, diferentemente de Jung, o psiquiatra, neurologista e terapeuta existencialista Viktor Emil Frankl (1905_1997) afirma uma ontologia dimensional, na qual o homem é concebido de corpo, psiquismo e espírito, sendo que essa última dimensão noética ou noológica não é hereditariamente transmissível; é uma esfera da existência que está acima da facticidade psicofísica e faz do homem um ser livre e responsável, além de albergador de uma religiosidade inconsciente (Eu espiritual imanente), oculta ou reprimida, mas capaz de prover relação/ligação com o transcendente divino/Deus (OLIVEIRA; AQUINO, 2014). Essa liberdade da vontade, espiritual autoconsciente, dá ao ser humano a capacidade de aceitar ou tentar modificar suas predisposições genéticas psico-físicas e 
sociológicas (PEREIRA, 2015). A vontade de sentido, por sua vez, é uma força básica pessoal que busca encontrar e realizar sentidos e propósitos. Essa busca (espiritual) por sentido de vida apresentase como uma característica constitutiva de autotranscendência da existência humana, capaz de encontrar sentido até em situações de sofrimento inevitável (FRANKL, 2017).

Nessa linha de pensamento filosófico-existencialista, mas agora também com influência da teologia cristã, Paul Tillich (1886_1965) define religião como o estado de se encontrar apoderado por uma preocupação última e entende a vida humana como constituída por dimensões física, química, biológica, psicológica, social e espiritual, que se entrecruzam e formam uma unidade. Esse espírito de cada ser humano pode ser transformado por ação do Espírito divino (com E maiúsculo), criando um novo ser (HIGUET, 2014). Nesse pensamento, aquela preocupação final é o que mais nos interessa ou que estamos até dispostos a morrer, e “acabará produzindo seus próprios dogmas, práticas, rituais, símbolos, relacionamentos e estruturas de apoio institucional"; podendo assim incluir não apenas religiões institucionalizadas, mas também ideologias como o marxismo e a Nova Era (BALBONI; PETEET, 2017, p. 4).

\section{RELIGIÃO E SAÚDE}

Apesar do interesse contemporâneo para os temas religiosidade e saúde, a pesquisa histórica comparada mostra que a saúde tem sido uma preocupação própria das religiões desde os tempos mais remotos, e "não encontra em nenhum canto da terra um mundo religioso que não tenha também uma 'função terapêutica'." (TERRIN, 1998, p. 151). Assim, testemunhos arqueológicos atestam a existência de terapias, inclusive como peregrinações antes do cristianismo: "Ísis para a tracoma, Asclépios em Epidauro, o profeta Jeremias cujo túmulo em Alexandria curava da picada mortal de serpentes [...]" (MESLIN, 2014, p. 210). Sobre religiosidade e saúde na antiguidade, Libório afirma:

A relação do homem das antigas religiões com o sagrado institucional ou instituído parece sempre contar com a presença e atuação de taumaturgos, xamãs, curandeiros, exorcistas, terapeutas e 
médicos, cujas funções são as mais diversas, às vezes, opostas e até sobrepostas.

De fato, a religiosidade humana, também na Antiguidade, está permeada de preocupações e atitudes diante de três companheiros inseparáveis do homem: o sofrimento, a doença e a morte. (LIBÓRIO, 2010, p. 12).

Essa atenção com o componente religioso da saúde do homem é mais explícita na medicina oriental, embora, desde o ano 372 d.C., os primeiros hospitais tenham sido organizados na Europa por monges e sacerdotes cristãos. Assim, até o fim da idade média, a Igreja continuou a construir e equipar hospitais em todo o mundo ocidental e foi responsável pela certificação de doutores para praticar medicina, mostrando que nossa noção de saúde moderna tem suas raízes em organizações religiosas (KOENIG, 2007).

No início do século $X X$, a religiosidade na saúde ocidental, principalmente nas áreas de psiquiatria, psicologia e neurologia, passou por uma fase de negligência ou oposição, ao generalizar as experiências espirituais como psicopatologias, com base em crenças e opiniões pessoais reducionistas de pioneiros da área de saúde mental, como Sigmund Freud e Granville Stanley Hall. Essa postura antirreligiosa se fez presente até a década de 1990, sendo hoje sobrepujada por milhares de estudos científicos antagonistas, incluindo ensaios clínicos e meta-análises, provenientes não apenas da Europa e Estados Unidos, mas também da Índia, Oriente Médio e Egito, (KOENIG, 2007; PANZINI et al., 2007; MOREIRAALMEIDA; KOENIG; LUCCHETTI, 2014).

A respeito desse aumento significativo de publicações científicas sobre espiritualidade e saúde, pesquisadores americanos publicaram um Handbook of Religion and Health (Manual de Religião e Saúde), onde mostram que o número de estudos quantitativos de boa qualidade sobre esse tema aumentou de 1200 no período de 1872 a 2000 para 2100 no período de 2000 a 2010 (ESPERANDIO, 2014). Também, revisão sistemática feita pelos brasileiros Moreira-Almeida e Lucchetti, juntamente com Koenig, em julho de 2013, no banco de dados PubMed National/Center for Biotechnology Information (PubMed) 
(2016), usando os descritores "(spiritu* [title] OR religio* [title] AND (clinical practice OR interview OR history) AND (psychol* OR psychiatr* OR mental)", encontraram 985 artigos empíricos e de revisão, os quais focalizam principalmente doenças mentais e, da mesma forma que publicações de associações profissionais, concordavam sobre a necessidade de se obter uma anamnese ou história espiritual quando do atendimento de pessoas com problemas de saúde (MOREIRA-ALMEIDA; KOENIG; LUCCHETTI, 2014, p. 177). A Associação Mundial de Psiquiatria, a Associação Americana de Psicologia, a Associação Americana de Psiquiatria e o Colégio Real de Psiquiatras possuem seções dedicadas ao estudo da religiosidade/espiritualidade (MOREIRA-ALMEIDA; KOENIG; LUCCHETTI, 2014).

Esse atual resgate científico da religiosidade nos faz pensar na necessidade da ampliação da definição de saúde como ausência de enfermidade e expressão de bem-estar físico, mental e social (WORLD HEALTH ORGANIZATION, 1948) para também bemestar espiritual, que o indivíduo e a coletividade podem alcançar por meio de um equilíbrio existencial dinâmico, mediado por fatores sociais, econômicos, políticos, culturais, ambientais, comportamentais e biológicos (FORTES; ZOBOLI, 2009; SCLIAR, 2007; PANZINI et al., 2011). Por enquanto, segundo Boero et al. (2005), em 1984, a dimensão espiritual tornou-se parte das estratégias dos Estados-Membros da Organização Mundial de Saúde (OMS) pela resolução OMS 37.13. E, em 1998, o Conselho Executivo da OMS recomendou a revisão da Constituição da OMS, a fim de incluir a dimensão espiritual na definição de saúde, mas a proposta não foi aprovada ainda. Sendo que, desde 1995, a espiritualidade é um dos componentes do instrumento de avaliação da qualidade de vida da OMS (BOERO et al., 2005; MOREIRA-ALMEIDA; KOENIG, 2006; WHOQOL GROUP, 1995). Mas, qual é mesmo a relação entre a religião/espiritualidade, a doença e a saúde? Por que devemos pesquisar mais sobre religião e saúde?

A importância de estudarmos religião e saúde reside não apenas no fato de que evidências científicas têm mostrado, na maioria dos casos, relação favorável entre maior religiosidade e melhor saúde, mas também no fato de que as pessoas têm encontrado em suas crenças e práticas religiosas um senso de controle existencial/psicológico e fonte de suporte social (KOENIG, 2012). Ao mesmo tempo, o envelhecimento populacional, com maior frequência de doenças crônicas/degenerativas, reforça a 
ideia de que seremos ou cuidaremos de pessoas com maior vulnerabilidade, exigindo uma saúde pública sustentável (SCHNEIDER, 1999). Diante disso, o cuidado com nossa religiosidade e espiritualidade deve ser estimulado como parte de uma "[...] saúde integral do homem hodierno em seu deslocar-se para a plenitude, construindo sua história, eivada de feridas e curas, enquanto dura fenomenicamente sua finita existência." (LIBÓRIO; GUIMARÃES, 2015, p. 219). Assim, um novo movimento de parcerias entre comunidades religiosas e sistemas de saúde, agora cada vez mais repletos de pacientes, podem oferecer uma importante solução complementar, "desenvolvendo-se sobre um precedente histórico que está em operação há quase dois mil anos." (KOENIG, 2012, p. 36).

\section{ANSIEDADE, DEPRESSÃO E COPING (ENFRENTAMENTO) RELIGIOSO-ESPIRITUAL}

É normal em alguns momentos de nossa vida reagirmos com estresse, ansiedade, medo ou tristeza, gerando luta, fuga ou resiliência. Porém, quando tudo isso é excessivo e nós desenvolvemos reações desproporcionais, comprometendo atividades usuais de trabalho, estudo, convivência, lazer ou socialização, estamos desenvolvendo distúrbio ansioso e/ou depressivo. O ansioso apresenta "medo do medo"; inquieta antecipação (apreensão) "Vai acontecer alguma coisa", diz o indivíduo. Já a pessoa com depressão apresenta anedonia (dificuldade ou quase incapacidade de ter prazer pelas coisas), variação circadiana do humor, ruminação obsessiva, autoacusação. "Gostaria de dormir e nunca mais acordar" (SERSON, 2016, p. 34, 42).

Nesse mesmo momento em que a prevalência de ansiedade e depressão vem aumentando, censos da Pew Research Center (2012) e do Instituto Brasileiro de Geografia e Estatística (IBGE, 2012, 2017) mostram que 83,7\% da população mundial, 92\% dos brasileiros, $91,7 \%$ dos nordestinos/paraibanos e $94,3 \%$ dos habitantes da cidade de João Pessoa estão envolvidos em alguma forma de prática religiosa ou espiritual. E, existem consistentes evidências que os indivíduos que têm mais religiosidade têm menos depressão, ansiedade, tentativas de suicídio e uso/abuso de drogas, e experimentam melhor qualidade de vida, remissão mais 
rápida dos sintomas depressivos e melhores resultados psiquiátricos (MOREIRA-ALMEIDA; KOENIG; LUCCHETTI, 2014).

No entanto, apesar de menos prevalente, o enfrentamento religioso negativo (por exemplo, conflitos com Deus ou com a comunidade religiosa, entender a doença como um castigo de Deus) ou o adoecimento mental de causa religiosa foi encontrado em algumas pesquisas. Algumas dessas mostram a influência negativa de religiões radicalmente fundamentalistas, nas quais o exercício do perdão e do amor incondicional nem sempre é praticado; por exemplo, ao lidar com pessoas que contraem doenças graves em razão de um comportamento pecaminoso [mal ético], tais como uso de drogas ou atividades sexuais promíscuas (ESPERANDIO, 2014; LIBÓRIO; GUIMARÃES, 2015).

A relação entre religião e saúde tem sido muito estudada nos casos de doenças mentais, trazendo à discussão a possibilidade de uma constante constitucional espiritual humana capaz de influenciar favorável ou desfavoravelmente na cura das pessoas. O tratamento junguiano busca levar o paciente a reconhecer que ele também apresenta um conteúdo mental saudável e bom, possível de ser reforçado e agir como força geradora de interação saudável do indivíduo com sua fa mília, com seu grupo social e com sua religião (GOMES, 2011, p. 90).

Nessa mesma visão otimista da existência, Frankl considera que a frustração da vontade de sentido pode causar a depressão, emergindo vontades de poder e prazer de forma acentuada que frustram cada vez mais a realização de sentido. Mas, a logoterapia dialógica acessa os recursos saudáveis do paciente, incentivando-o à noodinâmica - "tensão entre o ser e o vir a ser, o que a pessoa realizou e o que ainda deve realizar em sua existência" (AQUINO et al., 2015, p. 51). Assim, para Frankl, o "eu (espiritual) que decide" ou essencial "vontade de sentido" pode criar uma liberdade de decisão responsável, geradora de "sentidos" ou busca pelo "O Sentido ou suprassentido" na vida [Deus].

Segundo Paul Tillich, por medo de se perder, a pessoa pode se fechar numa existência autorrestritiva/preservativa/repressiva/legalista com desintegração. A (re)integração curativa somente é possível quando o espírito humano é tomado pelo Espírito divino que o transcende _ fundamento de nosso ser e sentido. A salvação 
histórica e eterna exige uma coragem autotranscendente chamada de fé, que é "a coragem de aceitar que somos aceitos por Deus" (HIGUET, 2014).

Esse uso da espiritualidade e da religião como mecanismo de manejar o estresse é um tipo de coping - palavra inglesa sem tradução literal em português que pode significar "lidar com", "manejar", "enfrentar" ou "adaptar-se a" (LAZARUS e FOLKMAN, 1984 apud PANZINI, 2007, p. 128). O coping religioso-espiritual (CRE) descreve o modo como os indivíduos usam sua fé para lidar com os problemas de vida (PARGAMENT, 1988). Dependendo da forma como esse CRE é utilizado, pode gerar efeitos favoráveis ou desfavoráveis à saúde dos crentes - pode ser um CRE positivo ou negativo. De acordo com o nível de passividade ou atividade, o CRE pode ter um dos cinco estilos: autodirigido - a pessoa confia mais em si mesmo e menos em Deus; de delegação ou evitativo - o indivíduo não age e entrega seu problema a Deus; colaborativo - o paciente age e pede a Deus que o ajude (PARGAMENT, 1988); de súplica - tenta-se influenciar a vontade de Deus (PARGAMENT, 1997 apud PANZINI, 2007); renúncia - após fazer tudo o que podia, o fiel renuncia a sua vontade e resigna-se à suprema vontade de Deus (WONG-MCDONALD; GORSUCH, 2000). O último tipo de coping citado baseia-se no conceito bíblico cristão de autorenúncia (PANZINI, 2007).

\section{TEOLOGIA CRISTÃ E VIDA DE LUTERO:AFLIÇÃO E BOM ÂNIMO}

A teologia cristã apresenta o mal, seja ético ou natural (doenças, acidentes), como sendo consequência do pecado deliberado de anjos rebeldes e dos primeiros seres humanos, os quais geraram uma herança de tendência à desobediência; mesmo perante uma consciência espiritual do que é certo ou errado e diante do sentido de vida supremo de glorificar e ter prazer em Deus. O mundo bom formado pelo supremo Criador foi deformado por suas criaturas racionais livres, necessitando ser reformado/restaurado pela ação redentora de Deus. Sendo assim, há necessidade pessoal do ser humano arrepender-se de seus erros, reconciliar-se com Deus e encontrar a salvação, a qual não é somente eterna, mas é também imanente, histórica. Nesse contexto teológico cristão, às vezes nos deparamos com pregações que enfatizam a necessidade bíblica do arrependimento universal, porém esquecem de expor que Deus enviou seu Filho ao mundo 
para que todo aquele que nele crer receba perdão divino e coragem para vencer as tribulações: "[...] no mundo tereis aflições, mas tende bom ânimo; eu venci o mundo." (Jo 16,33).

As biografias de Martinho Lutero mostram que ele era um monge católico agostiniano muito dedicado. Segundo Daniel K. Judd (2016), Lutero se considerava um bom monge, que se confessava periodicamente, mas sua consciência sempre o deixava em dúvida sobre se estava fazendo sempre a vontade de Deus, compatível com a salvação somente pelas obras. Com base nos escritos do próprio reformador, Judd levanta a possibilidade do mesmo ter desenvolvido uma depressão temporária, ligada ao legalismo ou escrupulosidade religiosa. Pois, Lutero se autocondenava e tentava vencer isso com mais trabalho, jejum, oração e confissão excessiva; esta considerada desnecessária pelos seus superiores... Sentia-se mais culpado perante Deus, configurando um CRE negativo autodirigido, que confiava mais nas obras feitas por si mesmo do que na graça de Deus, que aos seus olhos parecia puni-lo. Como muitos homens, ainda hoje, Lutero ainda não tinha uma compreensão ortodoxa da graça redentora de Jesus e pensava que seria capaz de agir moralmente de forma perfeita e suficiente para alcançar a vida eterna.

Mas a história de Lutero não parou ali. Ele foi convidado para fazer doutorado e, após estudar os Salmos e as Epístolas de São Paulo aos Gálatas e aos Romanos, entendeu que a Bíblia revela que a salvação vem de e pela fé em Jesus Cristo, para a glória de Deus:

As palavras "justas" e "justiça de Deus" atingiram minha consciência como um raio. Quando os ouvi, estava aterrorizado. Se Deus é justo [pensei], ele deve punir. Mas quando pela graça de Deus refleti, no quarto aquecido desta torre, sobre as palavras: "Aquele que por fé é justo viverá" [Romanos 1:17] e "a justiça de Deus" [Romanos $3: 21]$, logo cheguei à conclusão de que, se nós, como justos, devemos viver da fé e se o direito a escravidão de Deus contribui para a salvação de todos os que creem, então a salvação não será o nosso mérito, mas a misericórdia de Deus. Meu espírito foi, assim, aplaudido. Pois é pela justiça de Deus que somos justificados e salvos através 
de Cristo. Estas palavras [que antes me assustavam], agora me agradam mais. O Espírito Santo revelou as Escrituras para mim nesta torre. (JUDD, 2016, p. 328, tradução nossa).

À luz da teologia bíblica e do que se entende hoje como coping, Lutero modificou sua compreensão religiosa sobre perdão e salvação, foi abraçado pela ação restauradora de Deus e curado da depressão, configurando um CRE positivo estilo colaborativo. Em outras palavras, Lutero recebeu iluminação do Espírito Santo, compreendeu que seus pecados foram justificados pela fé em Jesus, recebendo transformação/regeneração revigorante de Deus, geradora de boas obras tão significantes, que foram capazes de reformar a Igreja de Cristo no mundo. 


\section{CONSIDERAÇÕES FINAIS}

A cosmovisão pós-moderna de relativismo ético, fuga de metanarrativas estruturantes e até de anticristianismo, além de um paradoxal misticismo religioso, tem trazido à humanidade um vazio existencial profundo. Diante dessa ausência de sentido de vida, a logoterapia de Viktor Frankl se apresenta como um dos caminhos da Psicologia que se contrapõe à razão instrumental e ao cientificismo mecanicista. Mostra a possibilidade de buscarmos em cada ser humano uma coragem, um bom ânimo, um sentido de vida que vem de Deus e glorifica Ele, encontra alegria nEle e se abre para estender a graça divina para outras pessoas (LESLIE, 2014).

Direção Espiritual ou Aconselhamento Pastoral Cristãos devem ajudar o paciente a encontrar feliz sentido de vida, perdão, salvação e alegria que transcenda os sofrimentos humanos reconciliação com Deus, com os outros e com a vida.

Para abordar um paciente a respeito de espiritualidade não é necessário o psicólogo/médico/psicanalista ser religioso, antirreligioso ou pró-religioso; mas, é essencial que ele entenda das relações positivas e negativas entre religião e saúde, e um pouco da teologia da religião do paciente. 


\section{REFERÊNCIAS}

AQUINO, Thiago Antonio Avellar et al. Logoterapia no contexto da psicologia: reflexões acerca da análise existencial de Viktor Frankl como uma modalidade de psicoterapia. Logos \& Existênca. V. 4, n. 1, p. 45-65, 2015.

ARMSTRONG, Karen. Em defesa de Deus: o que a religião realmente significa. Tradução de Hildegard Feist. São Paulo: Companhia das Letras. 2011. 398 p.

BALBONI, Michael J.; PETEET, John R. Spirituality and Religion Within the Culture of Medicine Spirituality and Religion Within the Culture of Medicine. New York: Oxford University Press. 420 p. 2017.

BOERO, M. E. et al. Spirituality of health workers:a descriptive study. International Journal of Nursing Studies. V. 42, p. 915-921. 2005.

ESPERANDIO, Mary Rute Gomes. Teologia e a pesquisa sobre espiritualidade e saúde: um estudo piloto entre profissionais da saúde e pastoralistas. Rev Horizonte. V. 12, n. 35, p. 805-832, jul./set. 2014.

FRANKL, Viktor E. Em busca de sentido: um psicólogo no campo de concentração. Tradução de Walter O. Schlupp e Carlos C. Aveline. São Leopoldo: Sinodal. Petrópolis: Vozes. 41ª edição, 2017. $184 \mathrm{p}$.

FORTES, Paulo Antonio de Carvalho; ZOBOLI, Elma Lourdes Campos Pavone (Orgs.). Bioética e saúde pública. $3^{a}$ ed. São Paulo: Loyola; 2009. Bioética e saúde pública: entre o individual e o coletivo. Cap. 1, p. 11-24.

GOMES, Antonio Maspoli de Araújo. Um olhar sobre depressão e religião numa perspectiva compreensiva. Estudos de Religião. V. 25, n. 40, p. 81-109, jan./jun. 2011.

HIGUET, Etienne Alfred. Saúde, doença e cura no pensamento de Paul Tillich: reflexões teológicas e pastorais. Rev. Pistis Prax. V. 6, n. 1, p. 167-188, jan./abr. 2014.

INSTITUTO BRASILEIRO DE GEOGRAFIA E ESTATÍSTICA. Censo Demográfico 2010: Características gerais da população, religião e pessoas com deficiência. 2012. 
INSTITUTO BRASILEIRO DE GEOGRAFIA E ESTATÍSTICA. O Brasil em Síntese. Censo 2010. 2017. Amostra Religião. Disponível em: https://cidades.ibge.gov.br/brasil/pb/pesquisa/23/22107?localidad e1=250750. Acesso em: 20 abr. 2018.

JOÃO. In: Bíblia: tradução Almeida revista e corrigida. Barueri: Sociedade Bíblica do Brasil, 1995.

JUDD, Daniel K. Clinical and Pastoral Implications of the Ministry of Martin Luther and the Protestant Reformation. Open Theology. V. 2, p. 324-337. 2016. DOI 10.1515/opth-20160027

KOENIG, Harold George. Religião, espiritualidade e psiquiatria: uma nova era na atenção à saúde mental. Rev Psiq Clín. V. 34, n.1, p. 5-7, 2007.

KOENIG, Harold George. Medicina, Religião e Saúde: o encontro da ciência e da espiritualidade. Tradução de luri abreu. Porto Alegre, L\&PM, 2012.

LESLIE, Robert C. Jesus e a Logoterapia: 0 ministério de Jesus interpretado à luz da psicoterapia de Viktor Frankl. São Paulo: Paulus. 2014.

LIBÓRIO, Luiz Alencar. Religiosidade e saúde integral no hinduísmo e budismo. Revista de Teologia e Ciências da Religião da Unicap. Recife, ano IX, n. 2. p. 9-39, jul./dez, 2010.

LIBÓRIO, Luiz Alencar; GUIMARÃES, Valtemir Ramos. Influências psicossociais e religiosas do fundamentalismo bíblico na saúde integral dos adeptos de uma Igreja. Paralellus. Recife, v. 6, n. 12, p. 217-236, jan./jun. 2015.

MATHERS, Colin D; LONCAR, Dejan. Projections of Global Mortality and Burden of Disease from 2002 to 2030. PLOS Med. V. 3, n. 11: p. 2011-2030, 2006. doi:10.1371/journal.pmed.0030442.

MOREIRA-ALMEIDA, Alexander; KOENIG, Harold G; LUCCHETTI, Giancarlo. Clinical implications of spirituality to mental health: review of evidence and practical guidelines. Rev Bras Psiquiatr. V. 36, n. 2, 2014.

MESLIN, Michel. Fundamentos de antropologia religiosa: a experiência humana do divino. Petrópolis: Vozes, 2014. 
OLIVEIRA, Karen Guedes; AQUINO, Thiago Antonio Avellar de Aquino. A logoterapia no contexto da psicologia da religião. Interações Cultura e Comunidade. V.9 n.16, p. 225-242, 2014.

ORGANIZAÇÃO MUNDIAL DE SAÚDE. Relatório Mundial da Saúde. Saúde mental: nova concepção, nova esperança. Lisboa, Coordenação Nacional para a Saúde Mental Alto Comissariado da Saúde, Ministério da Saúde de Portugal. 2002.

ORGANIZAÇÃO MUNDIAL DE SAÚDE; ORGANIZAÇÃO MUNDIAL DE MÉDICOS DE FAMÍLIA. Integração da saúde mental nos cuidados de saúde primários: uma perspectiva global. Lisboa, CLIMEPSI Editores, 2008.

PANZINI, Raquel Gehrke et al. Qualidade de vida e espiritualidade. Rev Psiq Clín. 34, supl 1; 105-115, 2007.

PANZINI, Raquel Gehrke et al. Validação brasileira do instrumento de qualidade de vida/espiritualidade, religião e crenças pessoais. Rev Saude Publica. V. 45, n.1, p. 153-65, 2011.

PARGAMENT et al. Religion and the problem-solving process: three styles of coping. Journal for the Scientific Study of Religion. V. 27, n.1, p. 90-104, 1988.

PEREIRA, Ivo Studart. Espírito e liberdade na obra de Viktor Frankl. Psicologia USP. V. 26, n. 3, p. 390-396, 2015.

PEW RESEARCH CENTER. The Global Religious Landscape: A Report on the Size and Distribution of the World's Major Religious Groups as of 2010. 2012. Disponível em: http://assets.pewresearch.org/wp-

content/uploads/sites/11/2014/01/global-religion-full.pdf. Acesso em: 20 abr. 2018.

SCLIAR, M. História do conceito de saúde. Physis. V. 17, n.1, p. 29 41, 2007.

SERSON, Breno. Transtornos de ansiedade, estresse e depressões: conhecer e tratar. São Paulo: MG Editores, 2016.

SCHNEIDER, Edward L. Aging in the third millennium. Science. V. 283, p. 796-7, 1999.

SMITH, Wilfred Cantwell. O Sentido e o Fim da Religião. São Leopoldo: Sinodal/EST., 2006. 
TERRIN, Aldo Natale. O Sagrado Off Limits: a experiência religiosa e suas expressões. São Paulo, Edições Loyola, 1998.

WHOQOL GROUP. The World Health Organization Quality of Life Assessment (The WHO-QOL). Position paper from the World Health Organization. Social Science and Medicine 41, 1403-1409. 1995.

WORLD HEALTH ORGANIZATION. Depression and other common mental disorders: global health estimates. World Health Organization, p. 1-24, 2017.

WONG-McDONALD, Ana; GORSUCH, Richard. L. Surrender to God: An additional coping style? Journal of Psychology and Theology. V. 28, n. 2, p. 149-161, 2000. 